\title{
Usos Da Linguagem Em Sentenças Judiciais Para Retificação De Nome E Sexo De Pessoas Transgêneras
}

\section{Language Uses In Court Decisions For Name And Gender Rectification Of Transgender Persons}

DOI: 10.54018/sssrv3n1-004

Recebimento dos originais: $30 / 11 / 2021$

Aceitação para publicação: 23/12/2021

\section{Marcia Teshima}

E-mail: teshima@uel.br

Edina Regina Pugas Panichi

E-mail: edinapanichi@sercomtel.com.br

\section{RESUMO}

Todo indivíduo ao nascer recebe um nome e, por intermédio de uma certidão de nascimento, passa a ser identificado e distinguido entre seus pares na vida em sociedade, símbolo da personalidade do indivíduo, capaz de particularizá-lo no contexto da vida social e produzir reflexos na ordem jurídica; portanto, é um direito personalíssimo e inato de todo ser humano e, em tese, imutável. Mas, e quando a identidade de gênero, que as pessoas sentem ter, discorda do que aparenta sua conformação biológica, realizada no momento do seu nascimento, parâmetro de atribuição de gênero, masculino ou feminino, como é o caso dos indivíduos transgêneros? Como eles se conduzem socialmente? Que obstáculos enfrentam para conseguir seu espaço e participar da vida em sociedade? Com suporte da Estilística Léxica, a pesquisa pretende mapear, por meio de uma precisa tipologia, os componentes de um fato social específico e os elementos que se deve ter em conta quando se avalia e se relata uma situação, ou seja, serão buscadas e discutidas características da linguagem, no âmbito das sentenças judiciais, sobre e para as pessoas transgêneras.

Palavras-chave: Linguagem. Estilística Léxica. Sentenças judiciais. Transgêneros.

\section{ABSTRACT}

Every individual at birth receives a name and, through a birth certificate, is identified and distinguished among his peers in life in society, symbol of the individual's personality, capable of particularizing him in the context of social life and producing reflexes in the legal order. therefore, it is a very personal and innate right of every human being and, in theory, immutable. But what about when the gender identity, which people feel they have, disagrees with what appears to be their biological conformation, held at the time of their birth, a parameter for the attribution of gender, male or female, as is the case with transgender individuals? How do they conduct themselves socially? What obstacles do they face in getting their space and participating in life in society? Supported by Lexical Stylistics, the research intends to map, through a precise typology, the components of a specific social fact and the elements that must be taken into account when evaluating and 
reporting a situation, that is, they will be sought and discussed. language features, in the context of court rulings, about and for transgender people.

Keywords: Language. Lexical Stylistics. Judicial sentences. Transgender.

\section{INTRODUÇÃO}

Diz-se que "transgeneridade é uma condição possível de indivíduos assumirem uma identidade de gênero, masculina ou feminina, diferente daquela que concorda com suas características biológicas, identidade essa designada por ocasião do seu nascimento" (MODESTO, 2013, p. 49-65). Portanto, transgênero é o indivíduo ${ }^{1}$ que se identifica com um gênero diferente daquele que corresponde ao seu sexo atribuído no momento do nascimento. $\mathrm{E}$, assim como os travestis, o transgênero não se identifica com o seu gênero biológico; o transgênero tem um sexo, mas se identifica com o sexo oposto e espera ser reconhecido e aceito como tal. Já o transexual é como uma "radicalização" do transgenerismo.

O sentimento de não pertencer ao gênero biológico é tão intenso que há um rechaço por tudo aquilo que é característica do seu sexo de nascimento. Por isso, o transexual é aquele que deseja alterar sua constituição biológica e fazer a mudança de sexo, sendo a cirurgia de redesignação sexual ${ }^{2}$ a única forma de se sentirem totalmente identificados e correspondidos na identidade de gênero que sentem pertencer, mas que não foi biologicamente atribuída.

Quando a identidade de gênero, que as pessoas sentem ter, discorda do que aparenta sua conformação biológica, realizada no momento do seu nascimento, parâmetro de atribuição de gênero, masculino ou feminino e, quando esse comportamento passa a ser exteriorizado em primeiro momento no espaço ${ }^{3}$ familiar, diz-se que é "birra" ou "graça" de criança4. Quando no espaço escolar, notadamente, na pré-adolescência e adolescência ${ }^{5}$ propriamente dita, diz-se que é típico de "rebeldia" e, portanto, permite-se como "válvula de escape aos hormônios à flor da pele". Mas, quando adulto, isso não é mais permitido ${ }^{6}$. E se trata de indivíduo transgênero, pior: diz-se que é "doente, anormal ou viado". Logo, são discriminados e relegados a uma vida periférica em sociedade.

Então, diante desse conflito entre o sexo biológico e o sexo com o qual se identificam, como esses indivíduos transgêneros se conduzem socialmente? Que obstáculos enfrentam para conseguir seu espaço e participar da vida em sociedade?

A família como o primeiro lugar de expressão, convivência e desenvolvimento de um indivíduo pode ser decisiva no sentido de ser (ou não) o instrumento facilitador de compreensão, aceitação e apoio ao indivíduo transgênero ao longo de sua vida. Mas, também, pode ser o primeiro espaço de incompreensão e repressão. A escola, por sua, como segundo espaço de expressão, convivência e desenvolvimento de um indivíduo, também, pode ser o

\footnotetext{
${ }^{1}$ Indivíduo aqui deve ser entendido como ser individual, conhecido pela sua existência única e indivisível, como sinônimo de cidadão, ou seja, um ser humano - homem ou mulher - inserido num ambiente social.

2 é o procedimento cirúrgico pelo qual as características sexuais/genitais de nascença de um indivíduo são mudadas para aquelas socialmente associadas ao gênero que ele se reconhece. É parte, ou não, da transição física de transexuais e transgêneros.

3 "Espaço" aqui deve ser entendido como um lugar que nós ocupamos enquanto ser humano e que, a despeito de todos serem livres e iguais perante a lei, ainda somos sujeitados, de algum modo, a uma autoridade ou poder.

${ }^{4}$ Sujeitados à autoridade dos pais, seja no modo de se vestir, brincar e comportar-se no padrão binário do pensamento ocidental: meninos têm pênis e meninas têm vagina, meninos brincam com meninos e meninas com meninas, etc.

${ }^{5}$ Agora, também, sujeitados à autoridade dos professores e sujeitados à instituição escolar com o uso de uniformes.

${ }^{6}$ A organização da sociedade ocidental ainda está baseada no padrão binário de homens e mulheres, sexo masculino e sexo feminino.
} 
lugar onde a rejeição, discriminação e a violência podem marcar de forma brutal, afastando-o, inclusive, dos bancos escolares. A sociedade, como o terceiro espaço, de efetivo lugar na vida adulta e que deveria permitir a expressão, a convivência e o desenvolvimento se revela cruel e discriminatória, pois, mesmo que o indivíduo transgênero possa - em tese - exercitar todos os seus direitos, a realidade se mostra distinta. $O$ nome é o seu primeiro obstáculo ${ }^{7}$. Assim, buscarse-á, identificar posicionamentos e tratamentos feitos discursivamente, por meio de recursos estilísticos, no âmbito das sentenças judiciais de retificação de nome e sexo, para ao final, elaborar crítica sobre e para as pessoas transgêneras.

\section{O NOME}

Ora, é sabido que todo indivíduo ao nascer recebe um nome ${ }^{8}$. E, por intermédio dele, ele passa a ser identificado e ganha status de pessoa física ${ }^{9}$ (ou natural), torna-se sujeito de direitos e obrigações, assim como é reconhecido e distinguido entre seus pares na vida em sociedade, inclusive, com reflexos após sua morte. Assim, o nome (aqui considerado prenome e sobrenome como a identificação civil de um indivíduo) é, pois, um dos principais elementos caraterizadores da pessoa natural. Trata-se de um símbolo da personalidade do indivíduo, capaz de particularizá-lo no contexto da vida social e produzir reflexos na ordem jurídica; portanto, é um direito personalíssimo e inato de todo ser humano. E a certidão de nascimento ${ }^{10}$ é o instrumento pelo qual se formaliza esse registro.

\section{Para Dias}

os direitos da personalidade constituem direitos inatos, cabendo ao Estado apenas reconhecê-los, dotando-os de proteção própria. São indisponíveis, inalienáveis, vitalícios, intransmissíveis, extrapatrimoniais, irrenunciáveis, imprescritíveis e oponíveis erga omnes. O nome é um dos direitos mais essenciais da personalidade e goza de todas essas prerrogativas. Reconhecido como bem jurídico que tutela a intimidade e permite a individualização da pessoa, merece proteção do ordenamento jurídico de forma ampla. Assim, o nome dispõe de um valor que se insere no conceito de dignidade da pessoa humana (DIAS, 2007, p. 210).

Portanto, em sendo o nome um direito personalíssimo, a regra geral é o da imutabilidade ou definitividade dele e, salvo situações excepcionais ${ }^{11}$, particulares e justificadas ${ }^{12}$, conservamos para toda a vida. Significa dizer que o nome é tão relevante para a pessoa que a ela se une, não tendo, pois, apenas um papel identificador para a coletividade e a família, mas o de incorporar a identidade subjetiva da pessoa. Pelo nome, o indivíduo ganha um lugar no mundo e o ambiente necessário para a construção da identidade e individualidade.

Mas, e quando o nome expõe o indivíduo a situações de embaraço, constrangimento, humilhação ou sofrimento? O que fazer?

\footnotetext{
${ }^{7}$ Transgêneros sofrem discriminação em processo seletivo de trabalho, atendimento médico em postos de saúde, até mesmo para contratar locação de imóveis, pelo fato de que, apresentam-se distintos (seja no comportamento, vestimenta e fala) da identidade civil.

${ }^{8}$ Toda pessoa tem direito ao nome, nele compreendidos o prenome e o sobrenome (art. 16 do Código Civil de 2002).

${ }^{9}$ Distingue-se da pessoa jurídica (entidade formada por indivíduos e reconhecida pelo Estado como detentora de direitos e deveres. O termo pode se referir a empresas, governos, organizações ou qualquer grupo criado com uma finalidade específica).

${ }^{10}$ Conquanto seja obrigação dos pais efetivarem, com prioridade, o registro de nascimento dos filhos, que é feito no Serviço de Registro Civil das Pessoas Naturais do lugar do parto ou da residência dos pais (art. 50 da Lei de Registros Públicos nº 6.015/73) isso nem sempre ocorre.

${ }^{11}$ Com o casamento ou união estável, homens e mulheres têm a opção de acrescentar o sobrenome do outro.

${ }^{12}$ A alteração do prenome que cause constrangimento, humilhação e sofrimentos pode ser deferida pela autoridade judicial desde que haja justificativa fundamentada para tal e que essa mudança não implique prejuízo a terceiros de boa-fé.
} 


\section{nome \\ 2.1. A Lei de Registros Públicos e os procedimentos à retificação do}

A Lei de Registros Públicos n $6.015 / 73$ previa que o prenome era imutável ${ }^{13}$; porém, em razão de alterações introduzidas pela Lei no 9.708/98, passou a vigorar com a seguinte redação: "Art. 56 - O interessado, no primeiro ano após ter atingido a maioridade civil, poderá, pessoalmente ou por procurador bastante, alterar o nome, desde que não prejudique os apelidos de família, averbando-se a alteração que será publicada pela imprensa."

Também, o artigo 57 dispõe que: "A alteração posterior de nome, somente por exceção e motivadamente, após audiência do Ministério Público, será permitida por sentença do juiz a que estiver sujeito o registro, arquivando-se o mandado e publicando-se a alteração pela imprensa, ressalvada a hipótese do art. 110 desta Lei." O artigo 58 estabelece ainda que: "O prenome será definitivo, admitindo-se, todavia, a sua substituição por apelidos públicos notórios ${ }^{144}$. Observe-se que, se é possível alterar o nome por conta de apelidos públicos notórios ${ }^{15}$, com maior razão quando se tratar de casos de: a) erros evidentes e grosseiros que não exijam qualquer indagação para a constatação imediata de necessidade de sua correção ${ }^{16}$, b) nomes que exponham ao ridículo quando, por exemplo, usados para ambos os $\left.\operatorname{sexos}^{17}, \mathrm{c}\right)$ nomes que causem vexame, embaraços e humilhações ${ }^{18}$ ou, ainda d) nomes que inflijam sofrimentos e constrangimentos em razão de que não se reconhecem como sendo do sexo biológico então atribuído pelo registro civil, como ocorre com os indivíduos transgêneros.

À luz da lei, excepcionando os casos com erros evidentes e grosseiros e que não exijam qualquer indagação para a constatação imediata de necessidade de sua correção pela via administrativa ${ }^{19}$, toda alteração do nome, ocorrida posterior

\footnotetext{
${ }^{13}$ Esta regra era pautada na segurança jurídica e objetiva evitar fraudes, sobretudo, impedir o uso indevido por pessoas com finalidade de buscar possível isenção de responsabilidade civil ou penal. Também, ainda há a Lei no 9.807/99, que instituiu o Programa Federal de Assistência a Vítimas e a Testemunhas Ameaçadas, prevê a substituição do prenome, e até do nome por colaborar com a apuração de um crime. A mudança pode ser determinada em sentença judicial, ouvido o Ministério Público. A alteração poderá, inclusive, se estender ao cônjuge, companheiro, filho, pai ou dependente que tenha convivência habitual com a vítima ou testemunha.

${ }^{14}$ Vide art. 58 da Lei de Registros Públicos (Lei ${ }^{\circ}$ 6.015/73).

${ }^{15}$ Como foram os casos do ex-Presidente da República Luiz Inácio Lula da Silva, Maria da Graça Xuxa Meneghel e Edson Pelé Arantes do Nascimento.

${ }^{16}$ A Lei no 12.100, de 27 de novembro de 2009, dá nova redação aos artigos 40, 57 e 110 da Lei nº 6.015, de 31 de dezembro de 1973 , tem o intuito de desburocratizar alguns dos serviços realizados pelos cartórios de registro de assentamento civil, possibilitando a retificação administrativamente quando se tratar de erro evidente e grosseiro, passíveis de prova documental.

${ }^{17}$ Nomes como Valdeci, Juraci, Iris, Nair, Nadir, Francis, Yuri, Remi, Sandy e Ivanir.

${ }^{18}$ Nomes como "Minaré Índio Brazileiro de Campos", "Esparadrapo Clemente de Sá", “Asteróide Silverio" ou "Dolores Fuertes de Barriga".

${ }^{19}$ Incluído pela Lei n ${ }^{\circ} 13.383$, de 26 de setembro de 2017.
} 
ao registro de nascimento, somente se efetuará por sentença judicial, devidamente averbada no assento de nascimento. Evidentemente, essa regra também pode ser aplicada ao indivíduo transgênero.

Dessa forma, o procedimento para a retificação do nome será o de jurisdição voluntária $^{20}$, no qual após requerimento da parte, ouvido o Ministério Público e os eventuais interessados, o juiz a ordenará no prazo de cinco dias. Em caso de impugnação, haverá produção de provas no prazo de dez dias, ouvindo-se os interessados e o órgão do Ministério Público, pelo prazo sucessivo de três dias, com decisão em cinco dias. Se não forem requeridas diligências, o juiz proferirá decisão no prazo de quinze dias, com base nos elementos constantes dos autos $^{21}$. Da decisão do juiz, caberá recurso em ambos os efeitos (art. 202 da Lei n. 6.015/73) pelo interessado, pelo Ministério Público ou por terceiro prejudicado.

Destaque-se que para o Direito as normas que asseguram a possibilidade de mudança com efeitos sobre a identidade social do indivíduo tratam o objeto que dá causa à demanda como erro ou falha (retificar) e como exceção (desvio do padrão). E, ainda que a lei permita corrigir algo involuntário ao indivíduo (nome e sexo sobre os quais não teve voluntariedade, escolha) e protegê-lo de danos que a vida em sociedade pode lhe causar (discriminação, humilhação, constrangimento e sofrimento), os termos em que ela trata desse direito são ainda ligados a conceitos de transgeneridade como erro, falha e exceção.

Com pouquíssimos avanços no escopo nacional ${ }^{22}$, o decreto federal $\mathrm{n}^{\circ}$ 8.727 23 , assinado pela ex-presidente Dilma Rousseff, em 28 de abril de 2016, dispôs sobre o uso do nome social e o reconhecimento da identidade de gênero de pessoas travestis e transexuais no âmbito da administração pública federal direta, autárquica e fundacional. Todavia, mesmo com essa iniciativa, permanece ainda a discriminação, a dificuldade de acesso a bens e serviços públicos como educação e saúde, assim como a restrição ao direito a um trabalho digno e, via de consequência, o espaço na vida em sociedade.

Como alento e resposta aos anseios desses indivíduos transgêneros, 0 Conselho Nacional de Justiça (CNJ) editou o Provimento ํㅜ 73, de 28 de junho de

\footnotetext{
${ }^{20}$ Artigo 719 do Código de Processo Civil de 2015 (Lei n ${ }^{\circ}$ 13.105/2015), no qual tutela interesse unilateral da parte que busca junto ao Poder Judiciário obter a pretensão do direito.

${ }^{21}$ Artigo 201 da Lei no $6.015 / 73$,

${ }^{22}$ Algumas conquistas no plano estadual e municipal como acesso a educação superior ou acesso aos serviços de saúde pública em Unidades Básicas municipais.

${ }^{23}$ Disponível em: http://www.planalto.gov.br/ccivil 03/ ato2015-2018/2016/decreto/D8727.htm. Acesso em 30 de junho de 2019.
} 
2018, que dispõe sobre a averbação da alteração do prenome e do gênero nos assentos de nascimento e casamento de pessoa transgênero diretamente no Registro Civil de Pessoas Naturais (RCPN), independentemente de ordem judicial. Com isso, a tendência será a diminuição gradual das demandas de retificação de assento de nascimento. Para tanto, bastará que o interessado declare perante o registrador do RCPN a vontade de proceder à adequação da identidade mediante averbação do prenome, do gênero ou de ambos.

Assim, diferentemente do que ocorria nos processos judiciais de retificação de assento de nascimento, onde o indivíduo precisava expor os fatos, relatando pormenores de sua vida, muitas vezes desde a infância, perpassando pela adolescência até a fase adulta, demonstrando suas dificuldades, constrangimentos e sofrimentos, ele o fazia por intermédio de uma linguagem aceita pelo direito para que a norma correspondente àquele fato (evento relatado em linguagem competente pelo advogado) pudesse ser aplicada. Mas, com o Provimento $\mathrm{n}^{\circ}$ 73/2018 que condiciona o deferimento da alteração mediante requerimento administrativo pelo interessado, a linguagem se reduz a um simples pedido administrativo.

\section{A LINGUAGEM E A CONTRIBUIÇÃO DA ESTILÍSTICA LÉXICA}

Ora, se a linguagem se realiza por relações intersubjetivas, pelo chamado processo comunicacional (ato da comunicação verbal), que pressupõe a existência de um emissor, um receptor, um código comum, uma mensagem, um canal que transmite a mensagem, um vínculo psicológico entre ambos e um contexto, no qual todos os elementos anteriores estão inseridos, com maior razão, do mesmo modo em um processo judicial. Tais vínculos se estabeleciam, inicialmente, entre o advogado e a pessoa transgênera quando da coleta dos fatos-relatos e, posteriormente, entre o Juiz e o transgênero, quando da realização da audiência e instrução, com a tomada do depoimento e oitiva de testemunhas. Nessa ocasião, havia a possibilidade de o indivíduo transgênero expressar seus sentimentos e vontades, emoldurando toda a sua produção discursiva, cujo conteúdo é, não raras vezes, permeado de emotividade do falante (ora dúvida, ora raiva, ora tristeza, ora conformismo, ora revolta, ora medo, ora receio). Toda essa produção textual e discursiva, seja ela por parte do indivíduo transgêneros, testemunhas, Ministério Público e Juiz, se materializam por intermédio do 
processo de retificação de nome e sexo perante o Poder Judiciário, especificamente, com a sentença, esta entendida como sendo o ato pelo qual 0 juiz põe termo ao processo, decidindo ou não o mérito da causa. Mas, a partir do Provimento no 73/2018, perde-se essa produção discursiva do sujeito.

Assim, com suporte da Estilística Léxica, a pesquisa pretende "mapear, por meio de uma precisa tipologia, os componentes de um fato social específico e os elementos que se deve ter em conta quando se avalia e se relata uma situação" (BRITO, PANICHI, 2013, p.7). Serão buscadas e discutidas características da linguagem, no âmbito das sentenças judiciais, sobre e para as pessoas transgêneras.

De acordo com Brito e Panichi:

A linguagem tem como finalidade básica a argumentação, [...] uma prática de relação social que vai gerar efeitos de sentidos que são produzidas pelas posições ocupadas pelos interlocutores, já que todo texto apresenta um sujeito enunciador sempre pronto a persuadir e convencer seu interlocutor. O discurso jurídico é, especificamente, um discurso argumentativo (BRITO, PANICHI, 2013, p.7)

Ademais, como no mundo do direito - em tese - só importa aquilo que for convertido em linguagem (Narra-me os fatos e eu te darei o Direito!), o acadêmico do curso de direito, assim como seus operadores, podem ter o benefício de melhor compreenderem os usos da linguagem nas esferas profissionais como construções de discursos sobre a para aqueles que buscam seus direitos.

\section{APORTE TEÓRICO E METODOLÓGICO}

Assim como a loucura e a doença mental, a transgeneridade está sendo constituída pelo "conjunto do que foi dito no grupo de todos os enunciados que a nomeavam, recortavam, descreviam, explicavam, contavam seus desenvolvimentos, indicavam suas diversas correlações, julgavam-na e, eventualmente, emprestavam-Ihe a palavra, articulando, em seu nome, discursos que deviam passar por seus" (FOUCAULT, 2008, p. 36). Então, "um enunciado tem sempre margens povoadas de outros enunciados"(FOUCAULT, 2008, p.110). 
[...] "não há enunciado em geral, enunciado livre, neutro e independente; mas sempre um enunciado fazendo parte de uma série ou de um conjunto, desempenhando um papel no meio dos outros, neles se apoiando e deles se distinguindo; ele se integra sempre em um jogo enunciativo, onde tem sua participação, por ligeira e ínfima que seja." (FOUCAULT, 2008, p. 112)

"Não se busca, sob o que está manifesto, a conversar semi-silenciosa de um outro discurso: deve-se mostrar por que não poderia ser outro, como exclui qualquer outro, como ocupa, no meio dos outros e relacionados a eles, um lugar que nenhum outro poderia ocupar. [...] que singular existência é esta que vem à tona no que se diz e em nenhuma outra parte?" (FOUCAULT, 2008, p. 31)

Foucault (1996, p. 10) vai além ao afirmar que, "o discurso não é simplesmente aquilo que traduz as lutas ou sistemas de dominação mas aquilo por que, pelo que se luta, o poder do qual nos queremos apoderar." E no campo do Direito o discurso é impregnado de uma linguagem própria, essencialmente persuasivo, vez que visa o convencimento do julgador.

Para Bally (1967, p. 28) “...El hombre no vive a solas consigo mismo; en todas sus jornadas se encuentra con otros hombres y debe contar com ellos. [...] el hombre es un animal social: el lenguaje es el producto de este instinto de sociabilidad." Em outras palavras, o homem foi feito para viver em sociedade, assim como a linguagem é a forma de interação que permite a aproximação e favorece o pensar e o agir entre os indivíduos. Em outras palavras, não há como pensar o homem sem a linguagem (BRITO, PANICHI, 2013, p.11).

Câmara Jr (1978), diverge de Bally, pois este não identificava a Estilística com uma Linguística do estilo, e afirma que "o estilo também pertence à língua, pois é um sistema simbólico que transponta do discurso". Segue, "O papel da estilística é depreender todos os processos linguísticos que permitem a atuação da manifestação psíquica e do apelo dentro da linguagem intelectiva." Dito de outro modo, para Câmara Jr (1978), "o estilo se caracteriza em regra por um desvio da norma linguística assente." Ele propõe em relação à linguagem, duas disciplinas linguísticas: a Linguística propriamente dita, como estudo da língua enquanto sistema representativo, enquanto a Estilística, ou Linguística do estilo, como estudo da língua enquanto sistema de expressividade. Isso significa que na estilística léxica, há uma tonalidade afetiva para as palavras, decorrente de uma natureza mais ou menos convencional atribuída às coisas designadas. Mas, a estilística léxica não para por aí. 
Para Câmara Jr (1978, p. 57), no inventário léxico de cada indivíduo há duas camadas que denominamos vocábulos transmitidos e adquiridos; os primeiros ganhos na infância, no meio doméstico, ao aprender a falar e associado às lembranças da experiência infantil. Já os segundos, hauridos nos mais diferentes níveis da estratificação social, contêm os termos fundamentais das atividades da vida cotidiana, ou 'populares', os mais intrincados. "As diferenças de tonalidade afetiva,[...] podem, uma ou outra vez criar discordância estilística entre o sujeito falante e o ouvinte..."

Ainda em relação às tonalidades emotivas das palavras, Martins (2008, p.106-107) defende que "os elementos emotivos que entram na constituição do sentido das palavras são de máximo interesse para a estilística". Destarte, palavras de significado afetivo que exprimem emoção, que exprimem julgamento, palavras com poder evocativo, etc. Isso não é indiferente ao indivíduo transgênero. Ao contrário, vivendo nas sombras e sem direito à voz. Ele permanece à margem das oportunidades de uma vida ao sol. Por intermédio da fala, o indivíduo pode ganhar vida e espaço em sociedade.

A natureza da pesquisa é documental e irá examinar sentenças judiciais prolatadas em processos de retificação de assento de nascimento de pessoas transgêneras, conduzidos pelo Escritório de Aplicação de Assuntos Jurídicos (EAAJ) da Universidade Estadual de Londrina. Para constituição do corpus da pesquisa farão parte as sentenças dos casos compreendidos no período de 2005 a 2019, incluindo processos físicos e eletrônicos (Projudi).

A definição deste período permite examinar apenas processos finalizados com sentença, portanto sem qualquer possibilidade desta pesquisa exercer influência ou colocar riscos às partes envolvidas. Nesse período, também, encontram-se algumas dezenas de processos que atendem ao descrito, volume esse que permite buscar marcas discursivas relevantes ao estudo.

O acesso a tais processos é facultado a qualquer docente advogado do EAAJ, portanto, membro da comunidade interna da instituição, por meio de login e senha individual cadastrado junto ao Tribunal de Justiça do Paraná. Os processos também podem ser acessados pela própria parte interessada (indivíduo transgêneros) mediante solicitação ao Juízo da causa que lhe disponibilizará um login e uma senha provisórios, permitindo-lhe assim 
acompanhar toda a tramitação de seu próprio processo. Na Comarca de Londrina, os processos de retificação de nome e sexo de transgêneros tramitam perante a Vara de Registros Públicos - e pelo fato desta Vara estar vinculada ao mesmo Juízo da 1a Vara de Família ${ }^{24}$ - o acesso aos processos é restrito, ou seja, apenas as partes envolvidas e seus respectivos advogados é que podem acessar. Contudo, se finalizado e arquivado o processo, com procuração outorgada pelo interessado e mediante justificativa fundamentada, o advogado poderá solicitar ao juiz o acesso ao processo judicial.

Assim, ainda que a pesquisadora proponente tenha tais credenciais para acesso aos dados, por ser membro da comunidade interna institucional e trabalhar no próprio EAAJ, o projeto conta com a concordância formal das instâncias superiores desse órgão suplementar (vinculado ao Centro de Estudos Sociais Aplicados e à Reitoria), inclusive, com aprovação pelo Comitê de Ética envolvendo seres humanos da UEL, junto à Plataforma Brasil, mediante comprometimento com a preparação do corpus de forma a eliminar toda e qualquer informação que possa identificar as partes envolvidas nos documentos das sentenças, bem como uso dos dados exclusivamente para esta pesquisa.

Será privilegiado o método indutivo de análise, partindo de uma proposição particular para uma geral para que se possa analisar o objeto para tirar conclusões gerais ou universais. Como pesquisa qualitativa, em lugar de formulação de hipóteses, buscam-se respostas para questões ou focos de interesses amplos, que vão se tornando mais diretos e específicos no transcorrer da investigação. 0 método a ser adotado nesta pesquisa será do empírico-indutivo.

Dessa forma, a pesquisa inicialmente será precedida de seleção dos casos judiciais, seguidos de levantamento bibliográfico (obras, artigos, revistas especializadas, tratados e convenções internacionais, legislações nacionais e jurisprudências relacionados ao Direito, à Estilística e à Crítica Genética), sobre mudança de nome de pessoas transgêneras e sentenças judiciais.

\section{CONTRIBUIÇÕES ESPERADAS}

Os principais benefícios são dirigidos aos estudos da linguagem, por meio da valorização das perspectivas da Estilística na construção de conhecimento, e ao Direito, pelo desenvolvimento, a partir do relato da pesquisa, de maior

${ }^{24}$ Tramitação em segredo de justiça. 
consciência quanto ao uso da linguagem e seus sentidos. Em suma, a pesquisa pode contribuir para minimizar usos de linguagem que provoquem sofrimento àqueles que buscam seus direitos. 


\section{REFERÊNCIAS}

BALLY, Charles. El lenguaje y la vida. Traducción de Amando Alonso, 5aㅡ ed. Buenos Aires: Editorial Losada, 1967.

BIASI, Pierre-Marc de. A genética dos textos. Tradução Marie-Hélène Paret Passos. Porto Alegre: EDIPUCRS, 2010.

BRITO, Diná Tereza de. PANICHI, Edina. Crimes contra a dignidade sexual: a memória jurídica pela ótica da estilística léxica. Londrina: Eduel, 2013.

BRASIL, Lei no 6.015/73, de 31 de Dezembro de 1973. Dispõe sobre os registros públicos, e dá outras providências. Disponível em: <http://www.planalto.gov.br/ccivil_03/LEIS/L6015original.htm>.Acesso em 11 ago. 2019.

CÂMARA JÚNIOR, Joaquim Mattoso. Contribuição à estilística portuguesa. $3^{\mathrm{a}}$ ed. rev. Rio de Janeiro: Ao Livro Técnico , 1978.

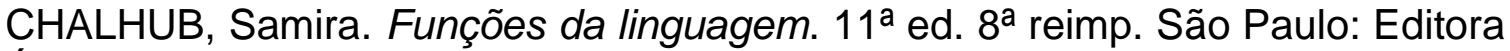
Ática, 2004.

CONSELHO NACIONAL DE JUSTIÇA. Provimento CNJ no 73/2018 - Dispõe sobre a averbação da alteração do prenome e do gênero nos assentos de nascimento e casamento de pessoa transgênero no Registro Civil das Pessoas Naturais (RCPN). Disponível em: https://www.cnj.jus.br/wpcontent/uploads/2018/06/434a36c27d599882610e933b8505d0f0.pdf. Acesso em 11 ago. 2019.

CRESSOT, Marcel. O estilo e as suas técnicas. Trad. Madalena Cruz Ferreira. São Paulo: Editora Martins Fontes, 1980.

DIAS, Maria Berenice. Manual de direito das famílias. 4aㅡ ed. Ver.atual.ampl. São Paulo: Revista dos Tribunais, 2007.

FOUCAULT, Michel. A arqueologia do saber. Tradução de Luiz Felipe Baeta Neves, $7^{\mathfrak{a}}$ edição. Rio de Janeiro: Forense Universitária, 2008.

FOUCAULT, Michel. A ordem do discurso. $7^{\mathfrak{a}}$ ed. São Paulo: Edições Loyola, 1996.

LABOV, Willian. Padrões sociolinguísticos. São Paulo: Parábola Editorial, 2008. LAPA, Manuel Rodrigues. Estilística da língua portuguesa. São Paulo: Martins Fontes, 1998.

MARTINS, Nilce Sant'Anna. Introdução à estilística: a expressividade na língua portuguesa. 4ํe. ed.rev. São Paulo: Editora da Universidade de São Paulo, 2008. ULLMANN, Stephen. Lenguaje y estilo. Traducción del inglés por Juan Martin Ruiz-Werner. Madrid: Aguilar Edicion 